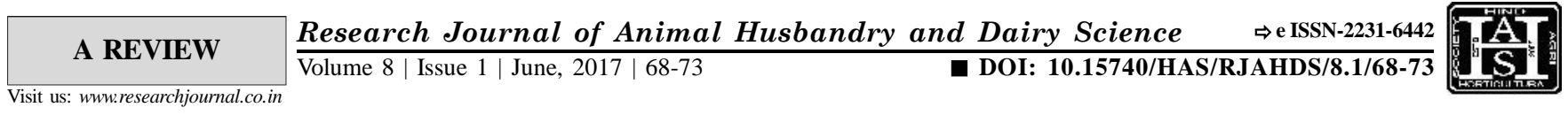

\title{
Bovine mastitis and management strategies for its prevention and control
}

\author{
MUNISH KUMAR AND JAGDISH GROVER
}

\begin{abstract}
Mastitis is a complex disease of milk producing animals having huge economic implications world wide. The disease is caused by various pathological agents and has both clinical as well as subclinical manifestations. Economic losses associated with mastitis originate mainly from a decrease in milk yield, discarded milk, veterinary services expenses, cost of veterinary medicines, reduced animal value, labour expenses, deterioration of milk quality and sometimes death of animals. Mastitis leads to significant changes in milk composition and thus, considerable changes in milk fat percentage and solid not fat (SNF) content of milk which renders milk quality deterioration. Management of lactating animals has quite a significant role in prevention of mastitis at a dairy herd. Awareness of dairy farmers can help to regularly monitor and ultimately reduce the number of cases of mastitis resulting in decrease in economic losses due to it, thereby enhancing of overall profitability.
\end{abstract}

KEY WORDS : Mastitis, Bovine, Prevention, Management

HOW TO CITE THIS PAPER : Kumar, Munish and Grover, Jagdish (2017). Bovine mastitis and management strategies for its prevention and control. Res. J. Animal Hus. \& Dairy Sci., 8(1) : 68-73 : DOI: 10.15740/HAS/RJAHDS/8.1/68-73. 